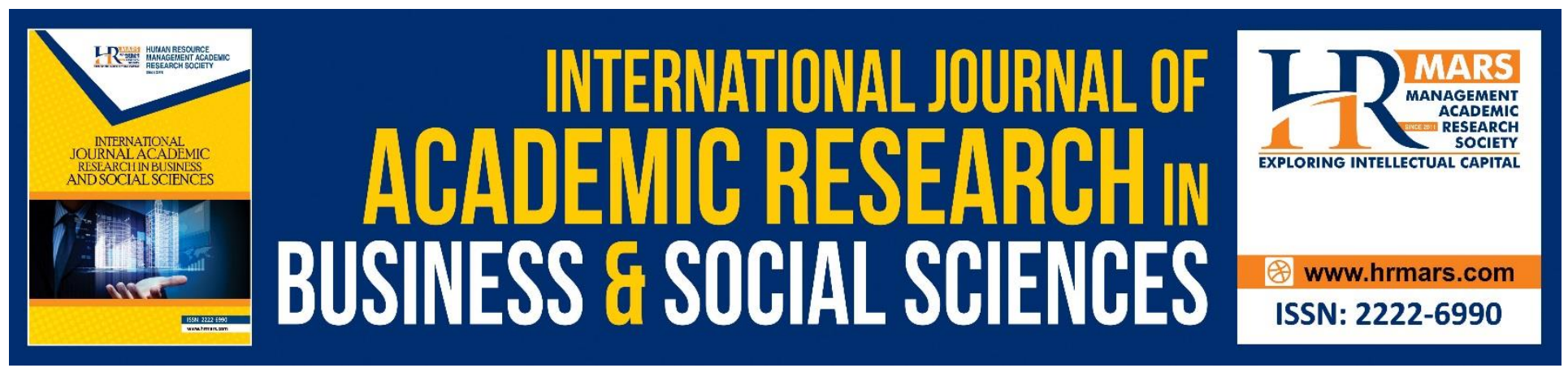

\title{
Past and Future of Human Resource Functions: Are We Done?
}

\author{
Hamid Masud, Wan Norhayate Wan Daud, Fakhrul Anwar Zainol, \\ Norfadzilah Rashid, Asyraf Afthanorhan
}

To Link this Article: http://dx.doi.org/10.6007/IJARBSS/v8-i11/5160

DOI: $10.6007 /$ IJARBSS/v8-i11/5160

Received: 21 Oct 2018, Revised: 17 Nov 2018, Accepted: 29 Nov 2018

Published Online: 03 Dec 2018

In-Text Citation: (Masud, Daud, Zainol, Rashid, \& Afthanorhan, 2018)

To Cite this Article: Masud, H., Daud, W. N. W., Zainol, F. A., Rashid, N., \& Afthanorhan, A. (2018). Past and Future of Human Resource Functions: Are We Done? International Journal of Academic Research in Business and Social Sciences, 8(11), 1149-1171.

Copyright: (c) 2018 The Author(s)

Published by Human Resource Management Academic Research Society (www.hrmars.com)

This article is published under the Creative Commons Attribution (CC BY 4.0) license. Anyone may reproduce, distribute, translate and create derivative works of this article (for both commercial and non-commercial purposes), subject to full attribution to the original publication and authors. The full terms of this license may be seen

at: http://creativecommons.org/licences/by/4.0/legalcode

\section{Vol. 8, No. 11, 2018, Pg. 1149 - 1171}

Full Terms \& Conditions of access and use can be found at http://hrmars.com/index.php/pages/detail/publication-ethics 


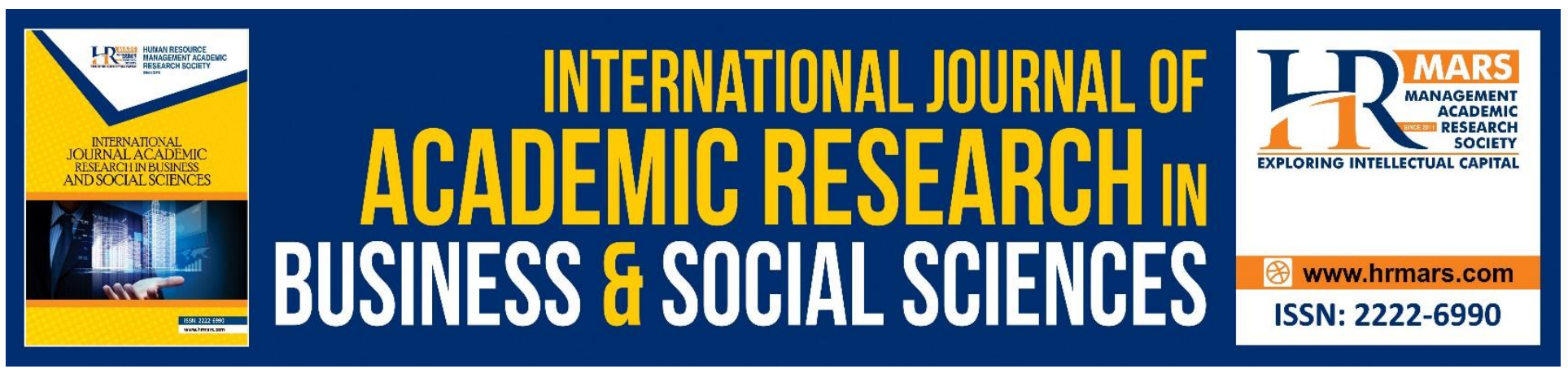

\title{
Past and Future of Human Resource Functions: Are We Done?
}

\author{
${ }^{1}$ Hamid Masud, ${ }^{2}$ Wan Norhayate Wan Daud, ${ }^{3}$ Fakhrul Anwar Zainol, \\ ${ }^{4}$ Norfadzilah Rashid, ${ }^{5}$ Asyraf Afthanorhan \\ University Sultan Zainal Abidin, Gong Badak, 21300 Kuala Terengganu, Terengganu \\ COMSATS University (Virtual Campus), Islamabad, Pakistan \\ Corresponding Author : wnhayate@unisza.edu.my
}

\begin{abstract}
Today, in the era of global competition, the importance of human resource function cannot be denied. It started its journey as a primarily administrative function, and now HR function is considered to be an essential ingredient of core strategic management policies. The current review is an attempt to analyze that whether HR function has reached its peak or still its journey is incomplete? HR scholars are looking for this answer and trying to explore its function in modern organizational settings. A brief discussion on HR literature followed by its evolution period is discussed. It is discussed that which HR functions are needed to adopt inside and outside approach to meet stakeholder's demand. Based on the review of HR literature, it is found that organizations not only need to follow inside/out approach but also outside/inside approach should be practiced for value addition. Furthermore, HR actions (at the individual, group and organizational level) are needed to improve organizational outcomes and to strengthen the role of organizational leadership.
\end{abstract}

Keywords: HR Practices, Turnover, Organizational Commitment, Employee Performance

\section{Introduction}

After the industrial and economic revolution, the role of the HR function has gained much importance to cope with these changes. Human resource management studies evolved more rapidly with the aim to increase productivity in complicated organizational settings. Though manufacturing development started in the 20th century, HR function could not improve its role in meeting existing organizational demands. That's why management practices in the earlier 20th century, which resulted in American industry to prosper, were described as inefficient, haphazard and unplanned management (Lescohier, 1935). In the modern era of globalization, competition among firms has increased which shifted the role of the industrial economy towards a knowledge-based economy. It has become challenging for firms to manage sustainable growth and to meet the stakeholder's requirements at the same time and thus making the role of HR function to be more crucial. 
Many HR professionals look for the same question that whether HR function has reached its final destination? It is a common practice that HR conferences end-up with the conclusion that HR merely serves as an administrative function to resolve the stated problems prevailing within organizations. These findings do not serve at a broader context and only lengthen the HR journey. In the past, HR function has undergone through many incremental developments in value addition and successfully contributing to organizational development. But the role of HR function is not limited to organize one-time event or process. There is a clear message from a current market situation that HR needs value addition to meet stakeholder expectations. There is a need for growth of HR function for value addition rather than focusing a single point of action. Thus the future of HR ends up with the aim of value addition. We will start this discussion with the emergence of $H R$ and its time-to-time development which took over time.

\section{Evolution of HR}

HR function gained importance with the emergence of industrial and economic revolution which took place back in the early 90s. During its earlier stage, HR function revolved around solving employee problems and value addition. In an early 20th century, HR function started growing and focused on industrial revolution, meeting organizational challenges and dealing with complex organizational structures to improve productivity and reducing employee turnover. During this phase, the HR function could not bring any fruitful development in HR literature. That's why management in the earlier 20th century was considered to be as inefficient, haphazard and unplanned (Lescohier, 1935).

\section{Early Stage Contribution}

Near the end of the 19th century, professional engineers came into front and leaded production processes. They introduced significant changes in management (Braverman, 1974). They're aimed at solving low productivity and high turnover problems and also to enhance developmental progress between humans and machines. Frederick W. Taylo, a renowned management scholar, is known as the father of scientific management and has contributed a lot in management literature (Drucker, 1955). He led the management theory by giving the idea of dividing big tasks into similar small tasks to save time and performing the same task by the same worker more accurately and correctly (Gilbreth, 1912, p. 50).

Not only Frank and Lillian Gilbreth but also other industrial psychologists played an essential role in the development of scientific management. Taylor heavily focused on time and tried to reduce process time to improve efficiency while Frank and Lillian Gilbreth used motion studies to study jobs and to reduce motions. Thus scientific management improved HR functions and introduced job analysis function in management literature. Job analysis is the fundamental HR activity which provides input for the fulfillment of HR tasks. It provides more appropriate techniques for selecting and training employees to enhance employee performance as well as compensating employees after the jobs (Drucker, 1977). Furthermore, it helps in setting wage and compensation packages for employees which are based on their performance. It not only increases organizational productivity but also helps in lowering turnover. Adding to this, scientific management pays more stress towards 
INTERNATIONAL JOURNAL OF ACADEMIC RESEARCH IN BUSINESS AND SOCIAL SCIENCES

Vol. 8, No. 11, Nov, 2018, E-ISSN: 2222-6990 @ 2018 HRMARS

hiring the right person for the right job (Nelson, 1980). In the same way, Gilbreth's and Taylor's continued their work and helped in achieving great development in HR function and general management (Drucker, 1977).

\section{Personnel Management aspect of HR}

World War 1 resulted imitated the need for recognizing HR as an essential component of the organization, and it started as a new professional field of study. Due to this, American industries had to face the problem of turnover. The significant shortage of labor, especially skilled and professional staff, was seen in 1914 due to immigration problems and also involving people in war. At that time, industries and employers needed to cope with the sudden rise in salaries and to meet the wartime production by managing the limited available manpower (Kochan \& Cappelli, 1984).

During the period of 1915-1920, business firms recognized the importance of centralizing employee management to tackle all relevant issues and performing scientific management practices effectively (Jacoby, 1985). Besides adopting several scientific management practices, organizations started adopting several industrial psychology practices to manage employee performance. All these employee management activities, later on, were handed over to the HR department. Later on, HR became a specialized profession; it had its policies and objectives aimed at maximizing employee efficiency and adding value.

\section{HR's Maintenance Mode}

During and after the World War 1, HR lost its importance due to the worldwide economic crisis (Watson, 1977). This shortfall of HR was temporary, and the problem was soon tackled due to rising challenges by unions and by the passage of the Wagner Act 1935. So, employers and organizations started to formally advance towards HR. This shifted the attention of employers from personnel management to industrial management. During the period of 1935-70s, employers focused on building good relations with unions and thus, the IR side of HR function became prominent. On the other side, personnel management was not given as much preference, so PM was termed as maintenance oriented, administrative and viewed as the lower level which does not contribute significant values to organizations (Burack \& Smith, 1982).

After World War 1 till the period of the 1970s, IR and PM aspects of HR were operating in maintenance stage due to economic stability and few shocks. Meanwhile, organizations started rationalizing employment relations with the help of internal labor markets (ILMs) which helped in simplifying the personnel management activities (Baron, Jennings, \& Dobbin, 1988). These ILMs used to focus on staffing at entry levels primarily, job security, the seniority system, promoting the employees internally, mechanized compensating systems and job security (Dulebohn \& Werling, 2007). So, HR lost its importance and focused only inside approach with little concern for the external environment. Though before this, HR was viewed as a necessary function for cost control and employee management, at that time HR was not viewed as a value-added function (cf., Ulrich, 1997). 


\section{Transformation of HR}

During the 1980s, HR started changing its role from an administrative function to the core business function whose merely focus was a value addition. Several organizational and environmental factors contributed to the shift of HR roles. These factors include a shift from manufacturing based economy to a knowledge-based economy, demographic changes, decreased unionization, employment legislation, international competition, and globalization. During this phase, personnel management (PM) was replaced by widely accepted "human resources management" or "Human resources" term. While PM termed employees as a cost to organizations, HR treated employees as a valuable asset to the organizations (Mahoney \& Deckop, 1986). PM used to focus on secondary activities which were not as useful while HR adopted a proactive which gave importance to human resource management expanded HR function within organizational setup (Prewitt, 1982).

\section{HR Administrative wave}

Transformation of HR can be characterized by three waves (Fig. 1). Because, PM preferred administrative role, so, the first wave of $\mathrm{HR}$ is characterized by an administrative wave. This wave worked on regulatory functions, delivery of HR services and administrative functions. This wave is characterized by a core organizational function whose main focus lied in improving administrative efficiency, pushing HR responsibilities to line managers.

\section{Practices wave of HR}

The second wave of HR comprises of HR practices wave. It focuses on the design of essential HR practices like hiring, career development, organizational structure and work processes. In this wave, $H R$ focuses on designing and implementing HR practices like hiring the right person for the right job. For this, the HR staff must work as a competent HR professional rather than an ordinary PM administrator who mere customizes different HR practices to meet organizational demands. 


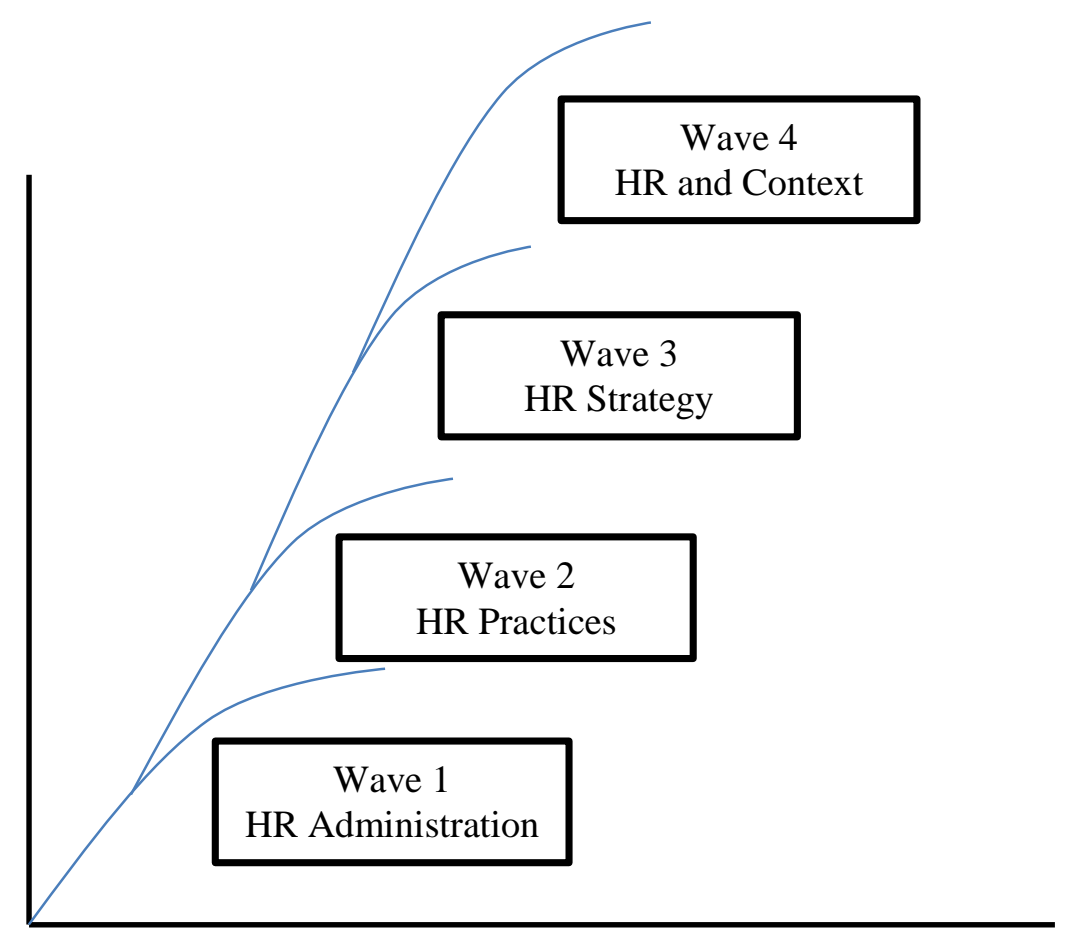

\section{HR Evolution Time}

\section{HR Strategy Wave}

3rd wave represents the HR strategy wave. It refers to the point where both HR practices and business strategies are aligned. The third wave is characterized by the phase where strategic HR connects HR practices to business success. So, HR extends its role beyond merely designing and implementing administrative policies and HR practices to solve organizational problems and to add value.

Involvement between HR and business strategy can be distributed in three types (Lawler \& Mohrman, 2003). First involvement represents the form in which strategic management has minimal involvement. Once the business strategy has been formulated, HR responds soon after it by aligning HR practices with strategy and to make sure that HR practices are consistent with a strategy so that desired organizational outcomes could be achieved. The 2 nd input and it involves getting sufficient information from the labor market and transmitting it to the strategic management team who formulate the strategy. The 3rd role of involvement represents the comprehensive partnership between HR and the strategic management team members. They play the role of partners from strategy development until strategy implementation.

When asked to HR professionals, "What is your biggest HR challenge?" they responded about wave 1 and 2. HR professionals have to deal with a lot of problems in formulating and implementing HR policies by doing it themselves. Without overcoming these problems, it's not possible to get desirable organizational outcomes.

Moving further from wave 1 and 2, several HR professionals should be asked the two-word question, "so what?" which relates to the outcome of the HR professionals and not only the work itself. For 
example, one of the HR professional responding that the primary objective of utilizing my and line manager's skills is to make better investments to meet organizational goals. This perspective of valueaddition is similar to that of scientific management and personnel management which aimed at attaining maximum organizational outcomes and reducing turnover. This perspective represents an inside-out perspective and moves towards wave 3 .

\section{Future HR: an outside/inside approach}

There is not the end of the destination of HR where HR experiences wave 3 and play the role of any of the business strategy. There is another "so that" question in which HR can move further from connecting HR to business (wave 3) to connecting HR with the broader context of outside business (wave 4). For example, an HR leader saying that my ultimate goal is to develop credibility with my line managers so that we can make an investment in our business to its goals and that we can respond to external needs and add value to organization and customers.

By responding to these two "so that" questions, HR professionals move from inside/outside approach to outside/inside approach. Outside/inside approach represents the way HR professionals act above and beyond the inside/outside approach. With the start of HR as a separate profession in the 1980s, it applied an inside/outside approach which returned remained limited to inside approach only. Thus it is suggested that future HR needs to go beyond the inside/outside approach.

By adopting outside/inside approach does not mean that HR no longer adds value by organizing and implementing HR practices and serving employees. Instead, it means that it creates values by aligning inside efforts and outside expectations approach together. For example, we want to build our strengths which in turn will strengthen others. Every HR practice can be further transformed by seeing its alignment with values it creates outside. This fact makes HR role broader beyond inside/outside approach by entirely reacting to organizational challenges and participating in strategy development and value addition.

\section{Getting from here to there: Wave 3 to Wave 4}

The question is that how HR move forward towards the outside/inside approach for adding value to the firm? Table 1 provides the answer to this question by addressing three issues briefly. First is related to HR's relationship with the business which involves business context in which decision making is done, and the other is stakeholders for whom business strategies are developed. Secondly, HR needs three components to achieve its targets, i.e., individuals, organizational and leadership. Third are the areas which need to be targeted to gain desired outcomes. In the next section, "what's next" will be proposed for each of these three areas. 
INTERNATIONAL JOURNAL OF ACADEMIC RESEARCH IN BUSINESS AND SOCIAL SCIENCES

Vol. 8, No. 11, Nov, 2018, E-ISSN: 2222-6990 @ 2018 HRMARS

Table.1 Overview of Future of HR

\begin{tabular}{|l|l|l|}
\hline & \multicolumn{1}{|c|}{$\begin{array}{c}\text { HR Approach } \\
\text { Current: Inside/Outside }\end{array}$} & \multicolumn{1}{c|}{$\begin{array}{c}\text { HR Approach } \\
\text { Future: Outside/Inside }\end{array}$} \\
\hline HR's focus & Redesign HR \& link to strategy & Use HR to link internal \& external stakeholder \\
\hline Relating HR \& business & Use HR to drive internal efficiency & Define HR value outside/inside \\
\hline Targets of HR for HR & HR results by talent management & Restructuring of HR function \\
\hline $\begin{array}{l}\text { Domains } \\
\text { investments }\end{array}$ & $\begin{array}{l}\text { Build HR departments within the organization; } \\
\text { There should be aligned, integrated, and } \\
\text { innovate HR practices for people, organization } \\
\text { and leadership; } \\
\text { There should be competent HR professionals } \\
\text { to add value; } \\
\text { Outside/Inside approach. }\end{array}$ \\
\hline
\end{tabular}

HR's relationship to the business: business context and stakeholders

An outside/in approach is developed when HR professionals understand their key stakeholders and business context. Entrepreneurs always welcome advice about their business growth. They are always in search of novel ideas which they could implement for their upcoming products and services. Entrepreneurs invest heavily in their upcoming products and designs. There are two general questions which most of the entrepreneurs failed to respond correctly. First, which issues you are going to address. Second, who will be your target audience? Reason for failing to respond to these questions is that they are unaware of the market realities. Here the role of HR professionals becomes more critical as they need to scan the external environment and stakeholders and synchronize it with their business strategies to add value.

\section{Business context factors}

Social, technological, economic, political, environmental and demographic trends are some of the business context factors which one must know to operate business functions in a foreign state. Social trends include social issues in the country. For example family patterns, lifestyle and health care. All internet usage related queries will resemble technological trends. Economic trends represent the economical situation which prevails within the state while political trends represent a political situation. Environmental sustainability relates to the economic situation while income, age, gender, race, and education are related to demographic trends.

Leaders must know these factors and trends so that they can better predict the market situation and their decisions can be helpful for business growth in that country.

HR professionals must be aware of HR work, ways of performing it and external factors that are directly associated with it. Social trends may affect an employee's strength while technological trends provide ways of expanding activities into the remote areas. Economic trends may directly affect with the growth and investment opportunities for products. All regulatory obligations are related to political trends prevailing in the country. Demographic trends help to attract talent through its hunt 
INTERNATIONAL JOURNAL OF ACADEMIC RESEARCH IN BUSINESS AND SOCIAL SCIENCES

Vol. 8, No. 11, Nov, 2018, E-ISSN: 2222-6990 C 2018 HRMARS

for locating the right person for the job. Future HR professionals must keep these factors into consideration so that they can respond to any sudden changes.

\section{Stakeholders}

Stakeholders are the 2 nd component of HR's relationship with business. Stakeholders have different sets of relationship with the organization. Either they affect it or become the victim of the organizational policies. Traditionally HR used to focus on internal (managers and employees) and external (government) stakeholders. Inside/outside perspective states that HR investments should be active enough to get desirable outcomes from employee's efforts and the line manager's skills to deliver on strategies. On the other end, outside/inside approach is related to the alignment of HR with external stakeholders who get value from HR work and also these stakeholders should influence HR work.

Fig. 2 shows the five stakeholders of HR which include both internal and external stakeholders. First one is related to customers. Customers are directly associated with the output produced. HR investment should engage customers with organizational outcomes. The reason is that when customers are satisfied with HR practices, then a secure connection is build up between customers and organization. For example, customers might be invited to a training session to get their opinion about the training of appropriate staff which serves them.

2ndly, there is a strong connection between HR investments and stakeholders confidence in future promises. If stakeholders have confidence in the firm's stability, then it is obvious the firm will be able to fulfill future demands. It is more likely that more than $50 \%$ of the market share can be traded if firms are financially stable enough to perform its activities.

Thirdly, if HR is working efficiently, then it can help in enhancing the firm's credibility in the community. HR can build its positive image by engaging themselves in social and welfare activates in the community. In this way, HR professionals can build a sharp image of the organization in the mind of external stakeholders.

Fig. 1 HR Transformation waves

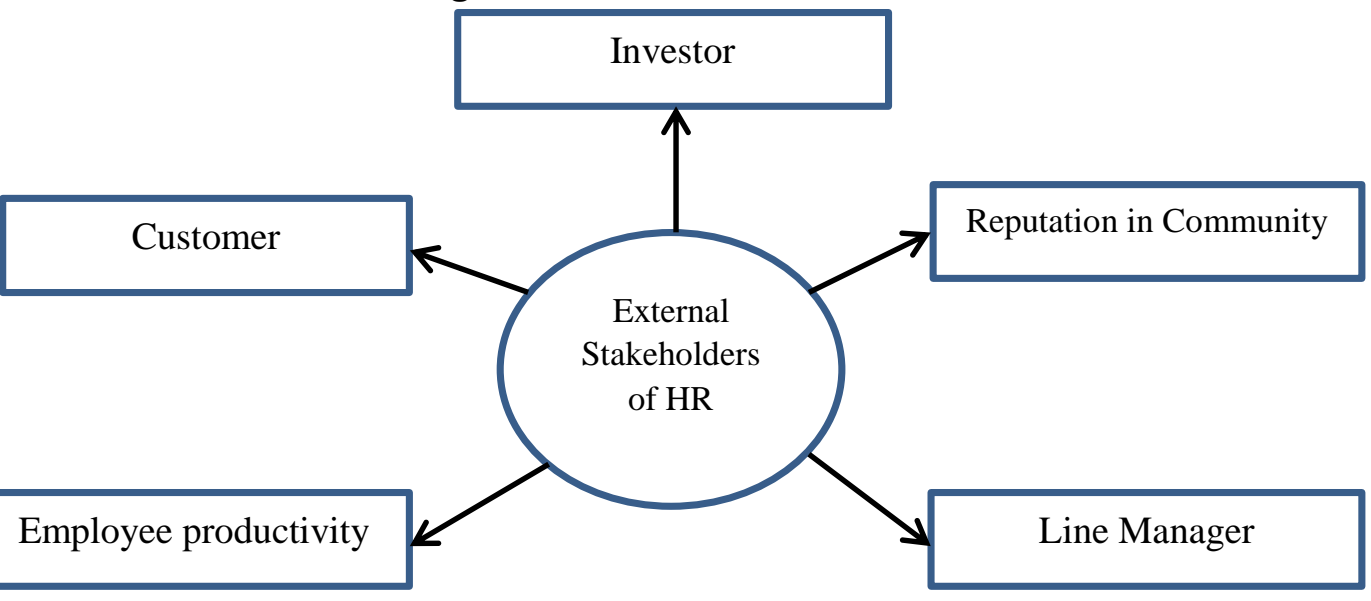

Five

Fig. 2

\section{Stakeholders of HR}

As $\mathrm{HR}$ is well aware of external stakeholders, so their discussion with business leaders is solely related to business perspectives. The topic of discussion not related to HR functions and objectives rather its 
objective is to share future goals. Whenever an HR professional gets a chance to be the part of strategic meetings, they are unable to contribute their viewpoint if it's related to exploration of new markets, financial stability of the organization or product innovation. Only debates relating to external stakeholders are part of HR discussions.

This outside/inside approach is a matter of interest for HR professionals to be considered as an HR transformation in the future. This will include community, investors, and customers. So, the following proposition can be stated:

Proposition 1: Outside/inside approach requires alignment of business perspectives with external stakeholders like community, investors, and customers.

It will add value to the organization and will be helpful in attaining favorable organizational outcomes. In this regard, future scholars might examine the relationship between HR perspectives (inside, outside/inside and inside/outside) and firm performance.

Proposition 1b: An outside/inside perspective will be related to customer satisfaction and high performance when it is compared to inside/outside and inside perspectives.

\section{Three targets or outcomes of HR work: individual, organizational, and leadership}

One of the major aspects related to outside/inside approach is that what contributions can be done by HR work when it is subject to business conversations or strategy formulations?

As discussed earlier, HR professionals can contribute in strategic meetings for sharing HR outcomes and not by giving suggestions related to HR activities (selection, training, and compensation packages, etc.) only. Therefore, HR must keep these three targets, individuals, organizations and leadership as a part of HR outcome to add value (Table 1). It holds the view that outside/inside approach goes beyond inside/outside approach (only by searching talents and getting fruitful outcomes). To get desired outcomes from strategy, employees must be skilled.

When the subject matter is prospects of markets, cost management or innovations, HR professionals should be concerned about individuals, organizations, and leadership related to such concerns. About individuals: which talent they need for effective implementation of this strategy? Which organizational capabilities needed to comply with strategy? Which behaviors of leaders are helpful in strategy implementation? Once these outcomes are finalized, then HR can play its role in designing and delivering HR practices. Below is a detailed overview of all the three work outcomes of HR.

\section{Individual ability (talent)}

There is one simple formula to judge the individual's capability of achieving tasks which are observing talent, their commitment, and contribution which they can add. Competence is related to individual's skills and values which are required for performing certain tasks today and in future. Simple, it can be said that hiring and selecting the right person for the right job.

But it should be kept in mind that competence is incomplete without commitment. If highly competent individuals are not committed, then there are equal chances that desired outcomes would be hard to achieve. Social exchange trends give importance to value and are of the view that employees who value their organizations, in return, they are also valued. So, future HR is required to 
assess and design such HR practices which are helpful in the selection of committed people and ways of fostering commitment among employees.

Commitment and talent of employees were two most significant factor of interest in past. Once future employees are not able to attain their targets, their commitment level diminishes with the passage of time and their productivity level is also disturbed. Contribution can only take place when employees feel that their personal needs are easily met, and their organization is fair enough to support them. Good leaders can instill positive thoughts in employees which motivate them to contribute positively. The contribution is only possible if employees feel that their personal needs are being met while staying in the current organization. Good leaders instill productive thoughts in employees for finding ways of contribution in their work. So, here HR can play its role by strategizing such policies which satisfy individual employees.

It can be said that competence, commitment, and contribution are connected to each other. If anyone of them is missing, then it's not easy to get desired outcomes. For example, if employees are not competent then regardless of their engagement and commitment, they cannot contribute as much as the talented ones. Adding to this, talent employees must be skilled individuals who show commitment and ability to contribute to organizational outcomes. HR leaders can play their role in this situation by pointing out the incompetency among individuals to managers who could cope with those individuals to improve their performance. So, the following proposition can be stated:

Proposition 2a: Role of future HR professionals is dependent on competence, commitment and contribution of employees to support organizational policies and adding value.

Proposition 2b: High-performance organizations will be characterized by talented employees who are not only committed and competent but also they are equally competent to add value.

\section{Organization capability}

When it is related to future outcomes, employees cannot achieve the desired HR work outcomes if they lack teamwork even if the employees are talented. Talented employees can be successful to some extent, but for organizations, teamwork is more important. In recent years, HR role has got importance for talent with a focus on an individual's competency. Besides all, HR sometimes fails to maintain a sustainable environment within organizations if it is unable to concentrate on teamwork and workplace culture. Future HR professionals also need to stress deep insights into individuals as well as organizations.

Generally, when we talk about the organization, we discuss its structure and define it by three broad factors: the First one is roles which explain that who is responsible to whom and who is accountable for work. The second factor is the rules. It covers all regulating principles for work and operationalization of organization. The third factor represents the organizational culture or processes within the organization. Combinations of all these three forms shape the organizational structure. Considering these factors, much of organizational restructuring has been done to rebuild, residing, re-engineer and reshape the organizations. All such changes are done purposely designed for future needs and cover the organizational design.

When top management and executives are asked to name any organizations they admire the most, they usually discuss those organizations who are successful in maintaining competence, commitment 
and contribution like Apple, Disney, Unilever or Microsoft. When executives are asked about levels of management in these organizations, they hardly know about it. No one admires any organization because of its routines or rules. Organizations are admired because of their capacity building like Apple is famous for its user-friendly products. People admire Microsoft and Google for their innovativeness and outside/inside approach.

An organization's capability lies in its ability to do things, deliver values. Capabilities define many of the intangibles towards which investors pay too much attention, an organizational culture which shapes behaviors of employees and a brand name which attracts customers. These capabilities also become the brand image of firm ways of performing HR practices. Duke (2011) found that HR professionals pay much attention towards organizational capability rather than individual competency development. McKinsey (2010) noted that in the future, individual competency development would be not as much significant as organizational capabilities. It was noted that $60 \%$ of people agreed that talent management and strengthening organizational capabilities are priorities of their firms. Very less proportion of successful firms who adopt capability building programs and are successful in adding value.

While competencies capture individual's ability, capabilities represent organizational identity (Ulrich \& Lake, 1990). Organizational capability is its ability to deal with its stakeholders and the environment. Future HR professionals strongly needed to build capabilities. Some of the accepted and traditional capabilities include customer service, quality, globalization, and efficiency. Future organizations might adopt the following capabilities to compete for global markets:

Risk Management: organizations that can anticipate and manage risk will be able to create value more successfully (DeToro, Fineis, \& Politzer, 2008).

Social responsibility: Socially responsible organizations will be more successful to attract investors, employees, and customers.

Simplicity: Organizations with simple organizational design will be successful in value addition as compared to firms with complex organizational designs (Ashkenas, 2009).

Connection: social networking is now very important for individuals and firms. Connecting employees, the connection among employees, firms, and stakeholders will surely help them to build social networks in the future around the world (PwC, 2007).

Innovation: Innovation will be expanded in future to include not only products but also business models, administrative structure and broadens business.

Identification and collaboration of these external stakeholders is an essential aspect of outside/inside approach for HR. Future HR professionals need to identify such external stakeholders who help them strengthening business capabilities.

Proposition 3. There is a strong need to identify and build organizational capabilities to add value and strengthen organizational strategy. HR is not only responsible for building traditional capabilities but also it focuses on building emerging capabilities like innovation, connection, and risk management. 
INTERNATIONAL JOURNAL OF ACADEMIC RESEARCH IN BUSINESS AND SOCIAL SCIENCES

Vol. 8, No. 11, Nov, 2018, E-ISSN: 2222-6990 @ 2018 HRMARS

\section{Leadership Brand}

Building strong leadership is the third target of HR outcome. Having a good leadership not only support strategy but also adds value to the organization (Table 1). Leaders are the ones who bring individuals and organizations together for solving problems of customers. There is a big difference between leadership and leaders. Leaders are those who lead others, having unique capabilities which frame individual behaviors while leadership is related to the capacity of the organization to build future leaders. Organizational leadership is far more important than Individual leaders. Keeping in mind the needs of the future market economy, future HR professionals not only need to develop individual leaders through development plans, feedback and coaching but also they need to invest in leadership development. There are five important aspects which HR professionals need to consider to develop a strong organizational leadership.

First, HR must be capable of showing that leadership can enhance performance, both inside and outside. In doing so, HR can quote examples of high performing firms who perceive their leaders as the ones who create value, and such firms regard them as good leaders (Bower, 2007). Such organizations, who believe in leadership depth, have deep insight into responding and managing sudden changes to executive strategy, business conditions and can respond to customer demands.

Second, HR is required leadership from outside/inside approach. Keeping in view the value creation from the outside/in approach, HR can define effective leaders from this approach. Often it happens that good leaders learn from success stories which prevail within the same organizational structure. In future, criteria for judging a leadership should start from the customer' point of view. For example, if a company is intended to launch its new brand and advertise it. Keeping in view the customer's response and preference, if leadership acknowledges customer response, then it is said to be effective leadership. When such criteria are set out for judging leadership, HR professionals then build high standards for good leadership.

Third, HR is required to assess the leadership's capabilities. Once standards are set for effective leadership, there is a need to assess the leadership scores to verify that either they meet the standards or not. Such assessment results are helpful in leadership development. In this way, leadership can be expanded when external stakeholder preferences are also involved in assessing good leadership. It is observed that companies now have internal as well as external assessment criteria to judge an individual's performance. Internal assessment is followed by viewing his relationship with team-members, and other groups wile outside performance is observed by analyzing his relationship with stakeholders. Assessment helps organizations to build a sharp image of leaders regarding their capacity for dealing future needs. HR professionals assigned with leadership strength can analyze their ability to respond to customer's demands.

Fourth is an investment in leadership. Traditionally, $70 \%$ of the leadership investment is done through learning and development while they are performing their job, $20 \%$ is done through feedback and $10 \%$ from training. There is a strong need to modify this model of leadership development, and it's better to invest 50\% leadership development through learning job experiences, $30 \%$ from training and $20 \%$ from learning experiences. It's a fact that learning comes from experiences and doing things. Though training is termed as merely a tourist activity where individuals come, observe and leave with certain things in their minds. But it keeps some images in their minds. The success of training is 
assessed with a positive change in attitudes, behavior, and productivity of employees (Blume, Ford, Baldwin, \& Huang, 2010). Guest raining is suggested which would not only help in fast learning but also help in shifting knowledge into practical activity as well. This is meant for a pre-work session to ensure that the learner is practically gaining what he is meant to perform later on in his professional career.

If we talk about learning experiences, most of the individuals learn from outside experiences in social and familial settings, during traveling, volunteer works or social network process. When organizations welcome such lifetime experiences, it broadens the learning spectrum of leaders. There is a need that HR should focus on current leadership development approaches for future leaders. For example, a firm can initiate philanthropy work as a development opportunity for its potential leaders. There is a definite need for HR professionals to consider the organization's current leadership investment plans to configure and develop it for future developmental needs.

Fifth is leadership measurement. It's a common practice that leadership investment is measured with the help of Kirkpatrick's (1994) scale. We can examine effective leadership in two distinct ways. Firstly, HR professionals need to find out that how leadership has delivered value to its stakeholders. This is one of the measures for examining leadership effectiveness. Secondly, examining return on intangibles. Future HR professionals need to link leadership efforts with ROI (return on intangibles) to assess their performance as it contributes to $50 \%$ shares of the company in the market.

Proposition 4. Future HR need to develop in-depth leadership. They can do it by assessing leadership performance, training needs and updating training modules of leadership.

\section{Four domains of HR investments}

It is suggested that future HR needs to add value to the organization and follow outside/inside approach. HR must consider leadership and organizational targets besides identifying key stakeholders and considering individual changes. There is a need to address the direction of HR investments. The reason is that there is so much critique on HR as well. To overcome this critique and hatred against HR. The first point that comes to mind is "what do you mean by HR"? HR may refer to HR function, HR metrics, HR Professionals or HR practices. Future investment should be done in each of these domains of HR. Investment affects the organizational value and helps to strengthen partnership role with stakeholders using outside/inside approach. In the next section, we describe that how investment can be made in each of these four HR areas.

\section{HR Department}

The first part of HR investment belongs to the HR department where investment should be made. Most of the HR functions have transformed in the last few decades. It follows restructuring HR functions and goals. These goals should be based on the organizational capabilities which are required for future success. For example, if an organization requires excellent leadership, speedy delivery of values and services as its capabilities, then these areas should be considered as goals of HR function. When goals of HR function and HR capabilities overlap with each other, HR will be more successful in contributing value. 
HR restructuring occurs when HR transformation and transaction are well defined. HR transaction work is related to routine processes of an organization which support it and help in administering it in daily work. Technology has helped a lot to perform these tasks. Besides administrative and strategic work, HR has undergone several changes in other departments like marketing and sales, data centers and finance).

HR departmental structure depends upon the structure of the business. It may be centralized or decentralized which leads towards three basic functionalizations of organization: diversified, holding or functional organization. It's HR responsibility to align its functions with any of these businesses operates. The most important thing is the alignment of HR function with the organizational structure.

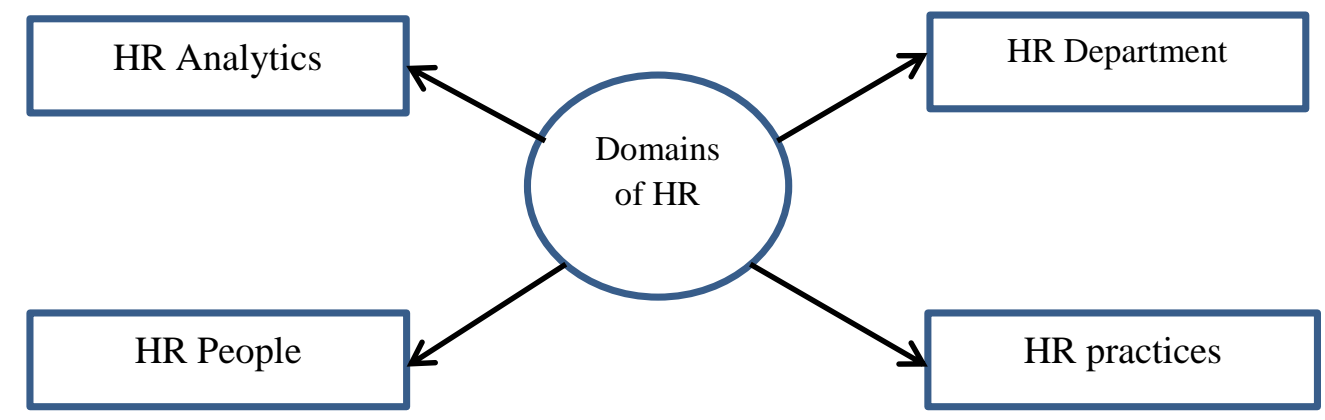

\section{Diversified/allied businesses}

Fig. 3 Four domains of HR

It has been observed that most of the companies are neither pure single nor holding companies. They are diversified in nature and have various business units in different segments of markets. One of the everyday things among them is that they have a consensus over the common strategic goals. A term, shared services, has been introduced to organize HR resources for these kinds of businesses (Cooke, 2006).

Shared services are divided into two parts, first are service centers which are aimed at facilitating employees and their administrative needs and these service centers heavily rely on technology while other is center of expertise which is linked to knowledge creation. Shared services seem to be centralized in nature, but in fact, it is not bounded by a centralized system. As the cost tended to rise in the 1990s which helped shared services to become popular among employees and different working groups. It is not possible for staff leaders to select a centralized system of approach as all business units are diversified in nature, and it is not possible to meet all the needs with a centralized system. That's why shared services became popular due to its balanced nature and flexibility which employees could use in any of the sudden change situations in markets. 


\section{Holding Company}

A company can be termed as a holding which owns multiple and irrelevant businesses at the same time. There are very few pure holding companies. There are some privately owned investment and equity firms who run such structure, for example, Blackstone, Berkshire Hathaway, and Carlisle. Blackstone owns Vanguard Health system, TRWA Automotive, and Houghton Mifflin. Berkshire Hathaway runs Fruit of the Loom, GEICO Insurance, NetJets and Dairy Queen.

For example, Berkshire Hathaway controls Fruit of the Loom, GEICO insurance, NetJets and Dairy Queen. Blackstone controls a different variety of companies like Vanguard Health Systems, TRW Automotive, SunGard System, NHP, and Celanese.

It is to be noted that in a holding company, there is little presence or complete absence of HR. Each business unit is dedicated towards the expansion of its business by managing its HR policies and structure. Berkshire Hathaway doesn't have any corporate HR department while NetJets and Dairy Queen have their HR departments. In fact, in all such corporations, all administrative tasks are managed by a group of businesses who profoundly analyzes market conditions, stakeholders and investor's relations. So there are very chances that such firms need an HR department. Even if there is a corporate HR department, it mainly deals with recruitment and compensation packages and has no influence on the overall administrative functions of the firm. If a holding company has a corporate HR department, it must ensure that the HR department is embedded in each business units and is performing well.

\section{Functional Organization}

When there is a single business which a company holds, then it solely focuses on its expansion. In such case, the role of HR is to support the business to grow through employee development. In the beginning, such companies don't have or manage a very few HR staff members. A company with 50 to 70 staff members hardly needs an HR expert as all administrative tasks can be accomplished with the help of line managers. But with the expansion of the company, the HR staff is hired for effective management. With the expansion of the organization, HR staff, as well as HR departments, also start growing. When there is only a single business strategy, the focus of HR is limited to the establishment and implementation of corporate-level policies. If the organizational structure doesn't demand, then there no need to add more line of businesses. It is interesting to note that there are only 15 to $20 \%$ of firms who hold the functional organization structure.

\section{From shared services to professional services}

Since the role of shares services has been widely appreciated and accepted by large organizations. The question arises that what is the next role of the HR organization? This is a big question mark for the future of HR. It can be seen that complete shared services doctrines have not been fully implemented by many of the organizations. To do this, a firm needs to understand organithe zation of HR firm within a firm entirely. Any professional service firm, like consultation firm, needs to cope with a challenge of convert knowledge client productivity. To do so, professional services firms have knowledge centers who are expert in their field of study. Also, such professional services firms have 
INTERNATIONAL JOURNAL OF ACADEMIC RESEARCH IN BUSINESS AND SOCIAL SCIENCES

Vol. 8, No. 11, Nov, 2018, E-ISSN: 2222-6990 C 2018 HRMARS

their client relation managers whose job is to identify customer needs and then utilizing their knowledge to satisfy their customer needs and expectations.

Proposition 5. Future HR needs to be sufficiently structured to meet requirements of business and to add value. Future HR department which operates within the firm as a professional services firms will add higher value to the firm.

\section{HR Practices}

Second are of HR investment is HR practices. There are large numbers of practices which make HR work more prominent. To summarize all, these HR practices have been divided into four main areas. First is related to people. HR shapes out working with people both inside and outside the organization. It includes planning, recruiting, training and developing. Second is related to employee performance. HR manages employee's performance by setting different performance standards, allocating different compensation packages and a system of feedback. Next segment is related to information. HR promotes the flow of information within the organization from side to side, from outside to inside and from top to bottom. The fourth segment is related to work and work outcomes. HR work includes that how work is done with the help of physical settings, workforce policies and with the help of different teams. All of these categories rely on each other for the effective functioning of outcomes and to promote HR policies. But, future HR professionals need to further work on alignment, integration, and innovation to entirely transform HR work.

\section{Alignment}

HR practices should align both with strategy and external stakeholders. By outside/inside approach, it is meant that HR professionals want to align and improve stakeholder's expectations and inside policies for sharing the accomplishment of shared goals. Customers may be considered as a part of training sessions for the designing training modules and as a facilitator. Once feedback is taken from outside (customers), it should be communicated inside so that employee performance could be improved. A good reward system can be helpful in getting favorable work outcomes and represents a practical implementation of HR practices within organizational settings. Customers can also be involved in different work designs to ensure that their expectations are fully met by the organization.

It is important to note that HR professionals should have full knowledge about customers. For this, they require spending their time on different sale calls. At first, customers interact with HR personnel and find it a bit hard. Later on, they understand the reason for HR professionals for being there (to strengthen the relationship with customers). When steps forward and ask customers that they are here to our purpose is to hire, train and unite people to sale best products which we promised to you, then customers will find it a good step and will move forward to for a relationship with that firm. It is equally possible that good firms call customers in their annual meetings and ask them about their capabilities so that they can get a response from customers about their products and services. Additionally, other stakeholders can also be included in discussion sessions to improve service delivery. 


\section{Integration}

Consider the example of a firm with disconnected $H R$ personnel $A, B$ and $C$ with expertise $D, E$ and $F$ to perform G, $\mathrm{H}$ but communicated the importance of $\mathrm{I}$, $\mathrm{J}$ and $\mathrm{K}$ in order to deliver $\mathrm{L}, \mathrm{M}$ and $\mathrm{N}$, then this practice will not work until each process is precisely integrated with the right choice. Same way, it is important to note that all HR practices should be integrated, not only with each other but also with the strategy, to get improved results. Otherwise, it's not possible to get favorable work outcomes. If different HR personnel work on different strategy, then different results can be seen which sometimes are not favorable. For example, if the company is committed to innovative products, then HR should design policies to help the company with innovative ideas. This integration works as a catalyst to HR practices. It has been found that integration of different HR practices leads towards higher outcomes (Becker, Huselid, \& Beatty, 2009) as the focus of all HR practices on a similar goal.

\section{Innovation}

Innovation can be regarded as an administrative process rather than a product or service. HR has gone through many innovations, but it's not possible to discuss all those in this review. Despite all these innovations, still, there is a need for managing employees, performance and work outcomes. Most of the innovations are due to the global competitiveness and overcoming worldwide challenges. For example, a firm may hire a good leader from the local market and assign him to work with a leader (who is leading in a mature market). So, the role of a mature leader is to transfer leadership qualities to a seasoned leader. In this way, innovativeness can be brought to the local market with the help of that seasoned leader. To move towards the process of innovation, one should be ready to experience new ideas, getting feedback from inside and outside the organization. When HR practices are aligned, integrated and innovative, HR can deliver talent, culture and ethical leadership to the company in the form of value addition to the firm; then it can be said that it serves its internal as well as external stakeholders. This requires HR to get new skills for future needs.

Proposition 6. Value addition can only be possible if an only if HR practices are aligned, integrated and innovative ideas. So, they need to focus on alignment, integration, and innovation of products. These foci focus on outside/inside approach and contribute to firm performance.

\section{HR Professionals}

HR professionals are part of HR investment and represent the third segment of it. Since the 1980s, there has been a significant concern in enhancing the skills of HR professionals. Investment in human capital will continue till they meet expectations of internal and external stakeholders. A collaboration of RBL group, University of Michigan and other professional associations have studied competencies of HR professionals for twenty years. 45,000 people were surveyed for this purpose. As a result of this survey and collaboration with other companies, following roles and skills of HR professionals were observed in their survey along with other empirical findings.

Firstly, it has been observed that around $20 \%$ of the HR professionals can contribute to organizational success. Other $20 \%$ are either unable or unwilling to take part in the productive activities. Rest $60 \%$ 
INTERNATIONAL JOURNAL OF ACADEMIC RESEARCH IN BUSINESS AND SOCIAL SCIENCES Vol. 8, No. 11, Nov, 2018, E-ISSN: 2222-6990 (C) 2018 HRMARS

of the individuals represent a significant portion of employees. They are still unable to determine that whether they contribute to organizational success or not. Do they make any progress?

Secondly, firms need a few HR professionals to continue their administrative work. Technology will continue to help HR professionals to improve administrative work in selecting and recruiting, in pay roll system maintaining employee performance. As firms have to deal with a variety of organizational challenges, but still they focus on their goal of increasing productivity. For this, they need to eliminate unnecessary activities.

Thirdly, as HR professionals are better able to enhance work outcomes with the passage of time, they become more balanced to apply different approaches to their work. Ulrich, Brockbank, Younger, and Ulrich (2012) and Ulrich, Younger, Brockbank, and Ulrich (2012) found that there are six roles of HR professionals which they play for the effective functioning of HR activities. First, some activists play an active role to strengthen a relationship of trust with the organization and also hold a good understanding of meeting customer expectations and think about successful business operations. The second role of HR professionals relates to individuals who go beyond formal limits to help the business grow and to develop a good relationship with stakeholders. Third are those individuals that work for the capability building to align organization culture with strategy. Fourth are those individuals who not only initiate change but also help them sustaining both at individual and organizational level. Fifth are those individuals who initiate and integrate innovations at an individual and organizational level. Finally, sixth are those who are technology users, who use technology to promote healthy practices within organizational settings.

In the survey of Ulrich et al. (2012), it was found that activists have more influence on the personal effectiveness of HR professionals than business outcomes. Productivity results are seen only because of technology proponents, HR innovators, and capacity builders. It is therefore needed a balanced approach from HR professionals to contribute to business positively.

As a way forward, there is a strong need to further improve these six domains of HR professionals. Also, there is also a need to invest in HR professionals so that they are better able to cope and adapt to unforeseen market challenges including globalization, risk, sustainability, and skills of HR professionals.

Proposition 7. To add value to the organization, it is not only required that HR professionals should acquire these six skills but also there is need to gain skills and expertise to adapt and manage future challenges.

\section{HR Analytics}

It is the fourth domain of HR investment. As HR and business are aligned together, so the importance of HR analytics cannot be denied (Boudreau \& Ramstad, 2007; Gibbons \& Woock, 2007). Without tracking and maintaining proper record of outcomes, it is not possible to properly implement HR decisions in the right directions. With HR analytics, HR investments can be better justified and improved. Improved HR analytics help in making the right decisions at the right time. With the help 
of HR analytics, HR moves forward with the right approach. Following are some suggestions regarding the future use of HR metrics.

First, the purpose of HR is to add value to the organization. Improved HR analytics help in achieving these measures. Some companies prepare scorecards, but they ignore the actual results occurring within the firm. This is like the situation when a sports fan is interested in statistics of the game, and he ignores whether the team wins or lose the match. Predictive Mean analytics (a path with outcomes) should be adopted rather than descriptive analytics (uses scorecards for comparison). So, means/end should be avoided. Instead of mean data, correlation analysis and predictive measures should be used to analyze the relationship between variables of interest. It will predict which employee is showing good and positive work behavior and confidence of investor. These are some of the good examples of predictive HR metrics.

Second, it should be kept in mind that doing the right should be followed rather than doing what is comfortable. In the past, it was a common practice of HR to count HR activities, like, how many managers got training programs and the number of managers who liked training programs (Fig. 7). There is a need to measure the outcomes of those activities instead of just measuring numbers. In turn, it will not only relate to the inside, but it will also affect stakeholders outside the organization. Sometimes it is not possible to estimate and track HR investments and outcomes. It is therefore suggested to use intermediate linkages to measure HR outcomes. It is important to track record of all activities and outcomes of HR along with business outcomes. Correlations and causal values represent the best HR work outcomes in this regard.

Third, measures should be focused and simple. It should be noted that the results of HR work outcomes can be quantified. In such a situation, HR would be able to propose accurate future suggestions. For example, it starts with collecting data from data warehouses (about employee's turnover, behavior, and performance) which is used for future predictions and to decision making. It is equally important for HR professionals to understand the trend in data for accurate decision making. Sometimes it is easy for decision-makers to understand those data and but sometimes data is complex and requires expertise from HR professionals to understand those trends and to make decisions later on. For example, sometimes companies want to start a business in emerging markets. So they need to understand how to implement HR practices in this situation. Once information about current trends in the market is collected, it is easy for the HR analyst to make further decisions.

Fourth, it is essential to understand that line managers should be given the task of accountability of HR analytics. The reason is that they better cope with work outcomes, so they are in a good position to analyze that how it can be improved. HR professionals are the ones who prepare blueprints for the organization. So, it is better to seek guidance from line managers regarding HR metrics to get maximum outcomes.

Fifth, it is important to use HR analytics in decision making. It is interesting to note that some of the HR professionals lack business knowledge. That's why many of the HR analytics enter the HR 
profession to avoidance of quantification of data. But it is not possible to make decisions without getting useful information in the form of quantifiable data. HR analytics is not complete without the support of statistics. So, without analyzing statistic measures, it's not possible to make the right decisions.

Proposition 8. HR professionals cannot take good decisions without HR analytics which ultimately will affect decision making. So, future HR professionals need to be strong in HR analytics.

\section{Conclusion}

This article provides a critical review of the literature on the HR practices and to answer the question that whether HR has reached its final point. To answer this, we just define "end point" or "final point" as adding value to the organization. Adding value is the core objective of HR which needs to be fulfilled. During the WWII, HR had only on inside approach and focused only administrative work. During the 1980s, HR transformed its functioning and moved towards the outside/in the path and focused towards value addition.

But, current market trends strongly demand outside/inside approach to connect with external stakeholders and to meet customer expectations. This approach helps HR to adopt policies which help in aligning internal and external stakeholders and to fulfill the demands of customers and the community. Following this approach, HR professionals go beyond their past experiences and efforts to add value and to align HR services and activities to meet all stakeholder's expectations.

After a brief overview of outside/in approach, a roadmap is given which started with stakeholder's interest and moved forward towards the individual, organizational level and then towards outcomes of leadership. It then shifted towards HR investments. $20 \%$ are already doing their best, while other $20 \%$ are somewhat contributing in different forms. We aim to get more than $60 \%$ of HR professionals to reach at this point to make them more committed and productive work-groups. To achieve this, several propositions have been given by past of past studies. Both practitioners and researchers can adopt these propositions. It is neither the end of HR nor beginning. Instead, it's a start for good HR for future work.

\section{References}

Ashkenas, R. (2009). Simply effective: How to cut through complexity in your organization and get things done. Boston, MA: Harvard Business Press.

Baron, J. N., Jennings, P. D., \& Dobbin, F. R. (1988). Mission control? The development of personnel systems in U.S. industry. American Sociological Review, 53,497-514.

Becker, B., Huselid, M., \& Beatty, R. (2009). The differentiated workforce: Transforming talent into strategic impact. Boston, MA: Harvard Business Press.

Blume, B. D., Ford, K. J., Baldwin, T. T., \& Huang, J. L. (2010). Transfer of training: A meta-analytic review. Journal of Management, 36,1065-1105.

Boudreau, J. W., \& Ramstad, P. M. (2007). Beyond HR: The new science of human capital. Boston: Harvard Business Review Press.

Bower, J. L. (2007). Solve the succession crisis by growing inside-outside leaders. Harvard Business Review, 85(11), 91-96. 
INTERNATIONAL JOURNAL OF ACADEMIC RESEARCH IN BUSINESS AND SOCIAL SCIENCES Vol. 8, No. 11, Nov, 2018, E-ISSN: 2222-6990 @ 2018 HRMARS

Braverman, H. (1974). Labor and monopoly capital. New York: Free Press.

Burack, E. H., \& Smith, R. D. (1982). Personnel management: A human resource system approach. New York: Wiley.

Cooke, F. L. (2006). Modeling an HR shared services center: Experience of an MNC in the United Kingdom. Human Resource Management, 45,211-227. http://dx.doi. org/10.1002/hrm.20105. DeToro,K.,Fineis,T.W.,\&Politzer,A.(2008).Designing a successful ERM function: Risk management structure and governance for the global insurance industry. Deloitt Touche Tohmatsu (Retrieved September 21, 2012: http://www.deloitte.com/assets/DcomIreland/Local\%20Assets/Documents/ie_ERS_DesigningASuccessfulERMFunction_Nov08.pdf). Drucker, P. E. (1955). The practice of management. New York: Elsevier. Drucker, P. E. (1977). People and performance: The best of Peter Drucker on management. New York: Harper's College Press.

Duke (2011). Learning and Development in 2011: A focus on the future. Duke Corporate Education Client Study (Retrieved September 21, 2012, http://www.dukece.com/ papersreports/documents/FocusFuture.pdf, Prepared by Duke Corporate Education). Dulebohn, J. H., \& Werling, S. (2007). Compensation research: Yesterday, today, and tomorrow. Human Resource Management Review, 17,191-207.

Duncan, G., \& Fass, G. (2009). Achieving high performance through shared services. Lessons from the masters. Accenture (Retrieved May 1, 2013 from: http://www.

accenture.com/SiteCollectionDocuments/PDF/Accenture_Consulting_Shared_Services_Report.pdf). Frigo, M. L., \& Anderson, R. J. (2011). Embracing enterprise risk management: Practical approaches for getting started. Committee of Sponsoring Organizations of the

Treadway Commission (Retrieved September 21, 2012:

http://www.coso.org/documents/Embracing ERM-GettingStartedforWebPostingDec110_000.pdf). Gibbons, J., \& Woock, C. (2007). Evidence-based human resources: A primer and summary of current literature. The Conference Board, Research Report E-0015 (Re-trieved Septembe 21, 2012, https://wpweb2.tepper.cmu.edu/evite/ebm_conf/conference\%20bd\%20HR\%20paper.pdf. Gilbreth, F. B. (1912). Primer of scientific management. New York: Van Nostrant. Goldman Sachs (2007). BRICs and beyond. Goldman Sachs Global Economic Research (Retrieved September 21, 2012: http://www.goldmansachs.com/our-thinking/topics/brics/brics-and-beyondbook-pdfs/brics-full-book.pdf).

Jacoby, S. (1985). Employing bureaucracy: Managers, unions, and the transformation of work in the twentieth century. New York: Columbia University.

Kirkpatrick, D. L. (1994). Evaluating training programs: The four levels. San Francisco: BerrettKoehler.

Kochan, T. A., \& Cappelli, P. (1984). The transformation of the industrial relations and personnel function. In P. Osterman (Ed.), Internal labor markets (pp. 133-162). Cambridge, MA: MIT press. Lawler, E. E., III, \& Mohrman, S. A. (2003). HR as a strategic partner: What does it take to make it happen? CEO Publication G 03-2(430). Center for Effective Organizations, Marshall School of Business, University of Southern California.

Lescohier, D. D. (1935). Working conditions. In J. R. Commons (Ed.), History of labor in the United States, 1896-1932, Vol. 3.(pp.3-385). New York: Macmillan. 
INTERNATIONAL JOURNAL OF ACADEMIC RESEARCH IN BUSINESS AND SOCIAL SCIENCES

Vol. 8, No. 11, Nov, 2018, E-ISSN: 2222-6990 @ 2018 HRMARS

Mahoney, T. A., \& Deckop, J. R. (1986). Evolution of concept and practice in personnel administration/human resource management (PA/HRM). Journal of Management, 12,223-242. McKinsey (2010). Building organization capabilities. McKinsey Global Survey Results (Retrieved September 21, 2012 http://www.mckinseyquarterly.com/Building_ organizational_capabilities_McKinsey_Global_Survey_results_2540).

Nelson, D. (1980). Frederick W. Taylor and the rise of scientific management. Madison: University of Wisconsin Press. Prewitt, L. B. (1982).

The emerging field of human resources management. The Personnel Administrator, 27(5), 81-87. PwC (2007). Managing tomorrow's people: The future of work to 2020. PriceWaterhouse- Coopers (Retrieved September 21, 2012: http://www.pwc.com.au/about-us/corporateresponsibility/assets/Managing-Tomorrows-People-Jan08.pdf).

Ulrich, D. (1997). Human resource champions: The next agenda for adding value and delivering results. Cambridge: Harvard Business School Press.

Ulrich, D., Brockbank, W., Younger, J., \& Ulrich, M. (Eds.). (2012). Global HR competencies:

Mastering competitive value from the outside in. New York: McGraw Hill.

Ulrich, D., \& Lake, D. (1990). Organizational capability: Competing from the inside out. New York: Wiley.

Ulrich, D., Younger, J., Brockbank, W., \& Ulrich, M. (2012). HR from the outside in: Six competences for the future of human resources. New York: McGraw Hill.

Watson, T. J. (1977). The personnel managers. London: Routledge \& Kegan Paul. 